\title{
DYSTROPHIA MYOTONICA: A MULTISYSTEM DISEASE
}

\author{
F.Y. DALAL, F.F.A.R.C.S., E.J. BENNETT, F.F.A.H.G.s., \\ P. PRITHYL RAJ, F.F.A.h.C.S., AND D.G. LEE, M.D.
}

\section{INTRODUCTION}

AN ANAESTHEsiologist is aware of the need for caution when confronted with a patient suffering from a myotonic syndrome. On reviewing the literature, ${ }^{1,2}$ it becomes evident that the stress has been on the myotonic aspects of the disease. However, dystrophia myotonica is a multisystem disease, and the following case report and related discussion illustrate the many facets which need consideration. ${ }^{3}$

\section{Case Report}

A 51-year-old white male was scheduled for excision of a malignant melanoma on the left arm with a radical axillary dissection. He was a confirmed case of dystrophia myotonica, diagnosed ten years prior to the present admission, although he had noticed difficulty with hard manual work for a long time prior to this diagnosis.

He complained of drooping eyelids and volunteered that his heart "skipped every so often". He was hospitalized for this, but no definitive diagnosis was made. As medication he was on Dilantin $100 \mathrm{mg}$ three times a day and three grains of thyroid extract four times daily.

Physical examination revealed a debilitated man confined to a wheel chair, with typical myopathic facies and frontal baldness. His neck was slender, with bilateral sternocleidomastoid atrophy. Cardiovascular examination was insignificant apart from an occasional extrasystole. The testes were atrophic. His extremities showed distal muscle atrophy and a positive thenar tap.

The chest X-ray was unremarkable. The EKG showed prominent $U$ waves and poor $R$ wave progression in the early $V$ leads. Pulmonary function tests revealed a mild restrictive defect (Figure 1 ).

Laboratory findings revealed a Hb of $12.6 \mathrm{gm} \%$, Het 40 , Total proteins $7.0 \mathrm{Gm} \%$, Alb 5.4 Gm\%, Cholesterol $225 \mathrm{mg} \%$, Phos $3.2 \mathrm{mg} \%$, Ca $9.1 \mathrm{mg} \%$, Uric acid $2.5 \mathrm{mg} \%$, Creatinine $0.4 \mathrm{mgg}$, Total Bilirubin $0.55 \mathrm{mg} \%$, Alk. phos. $100 \mathrm{mU} / \mathrm{ml}, \mathrm{LDH} 24$ $\mathrm{mU} / \mathrm{ml}$, SGOT $35 \mathrm{mU} / \mathrm{ml}, \mathrm{Cl} 104 \mathrm{mEq} / \mathrm{L}, \mathrm{CO}_{2}$ content $28 \mathrm{mEq} / \mathrm{L}, \mathrm{K} 4.3 \mathrm{mEq} / \mathrm{L}$, $\mathrm{Na} 143 \mathrm{mEq} / \mathrm{L}$, BUN $8 \mathrm{mg} \%$, Glucose $55 \mathrm{mg} \%$. (The CPK was $7 \mathrm{U}$ and PBI $5.4 \mu \mathrm{G} \%$ when performed three weeks postoperatively.)

Premedication was atropine $0.6 \mathrm{mg}$ subcutaneously one hour preoperatively. Anaesthesia was induced with $350 \mathrm{mg}$ of thiopentone, 2.5 per cent solution, given slowly, and $7 \mathrm{mg}$ of pancuronium was injected immediately after the loss of lid reflex. Anaesthesia was maintained with $70 / 30$ mixture of $\mathrm{N}_{2} \mathrm{O} / \mathrm{O}_{2}$, supplemented with fentanyl. Incremental doses of pancuronium $(1.5 \mathrm{mg})$ were given at 70 and 125 minutes after the initial dose.

-Department of Anesthesiology, University of Texas Southwestern Medical School at Dallas, Dallas, Texas 75235. 


\begin{tabular}{|c|c|c|c|c|}
\hline $\begin{array}{l}\text { Broncho- } \\
\text { Dilators }\end{array}$ & Obs. & Pred. & \% Pred. & $\begin{array}{l}\text { \%o Own } \\
\text { FEV }\end{array}$ \\
\hline $\begin{array}{l}\text { FEVC } \\
\text { (liters) }\end{array}$ & 2.19 & 4.31 & $50 \%$ & \\
\hline $\begin{array}{l}\text { FEV } 0.5 \\
\text { (liters) }\end{array}$ & 1.20 & 2.44 & $49 \%$ & $55 \%$ \\
\hline $\begin{array}{l}\text { FEV 1.0 } \\
\text { (11ters) }\end{array}$ & 1.75 & 3.35 & $53 \%$ & $80 \%$ \\
\hline $\begin{array}{l}\text { MVV } \\
\text { (L Min.) }\end{array}$ & 60 & 146 & $41 \%$ & \\
\hline
\end{tabular}

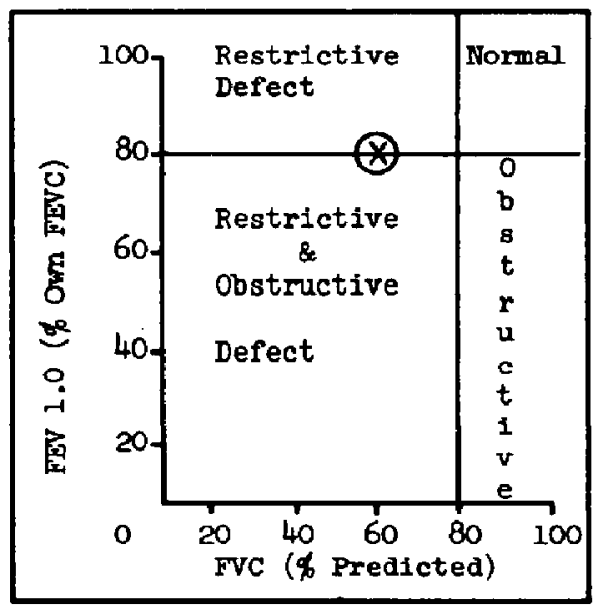

FigURE 1

EKG, temperature, urine output, and blood gases were monitored throughout the procedure. Blood samples were taken for the measurement of plasma cholinesterase at appropriate times during anaesthesia.

At the end of the operative procedure, which lasted $3 \%$ hours, the residual neuromuscular blockade was reversed with an intravenous dose of $5 \mathrm{mg}$ of neostigmine with $2 \mathrm{mg}$ of atropine. Even though the reversal was complete, the endotracheal tube was left in place to ensure an adequate airway. His postoperative course was uneventful.

\section{Quantitative and Qualitative Measurements of Patient's Plasma Cholinesterase Activity}

Samples of blood were collected during anaesthesia, centrifuged and the plasma collected. Plasma cholinesterase activity was measured by the Acholest ${ }^{*}$ test paper and by the method of Kalow and Lindsay ${ }^{4}$ on a double beam Perkin-Elmer Hitachi 1204 spectrophotometer. The substrate used was benzoyl choline $\left(2 \times 10^{-4} \mathrm{M}\right)$, and measurements were made at $240 \mathrm{~m} \mu$. The dibucaine number was measured by the method of Kalow and Genest. ${ }^{5}$

\section{Results}

Spectrophotometrically, the preanaesthetic plasma cholinesterase activity and dibucaine number were 220 units and 70 respectively (Figure 2). Acholest test time was 19 minutes (Figure 3). Twenty minutes after the induction dose (vide supra) of pancuronium (Figure 3), the plasma cholinesterase had decreased by 40 per cent (Figure 4). This activity improved, as seen in Sample 3 (Figure 4), but decreased again to 60 per cent of the control value after the first incremental dose of pancuronium. Samples 5 and 6 followed a similar pattern (Figures 3 and 4). Acholest test times, as shown in Figure 2, had a similar trend in the activity of plasma cholinesterase.

'Acholest (Cholinesterase Test Paper), E. Fougera \& Co., Inc., Hicksville, N.Y. 11802. 


\section{PSEUDOCHOLINESTERASE ACTIVITY}

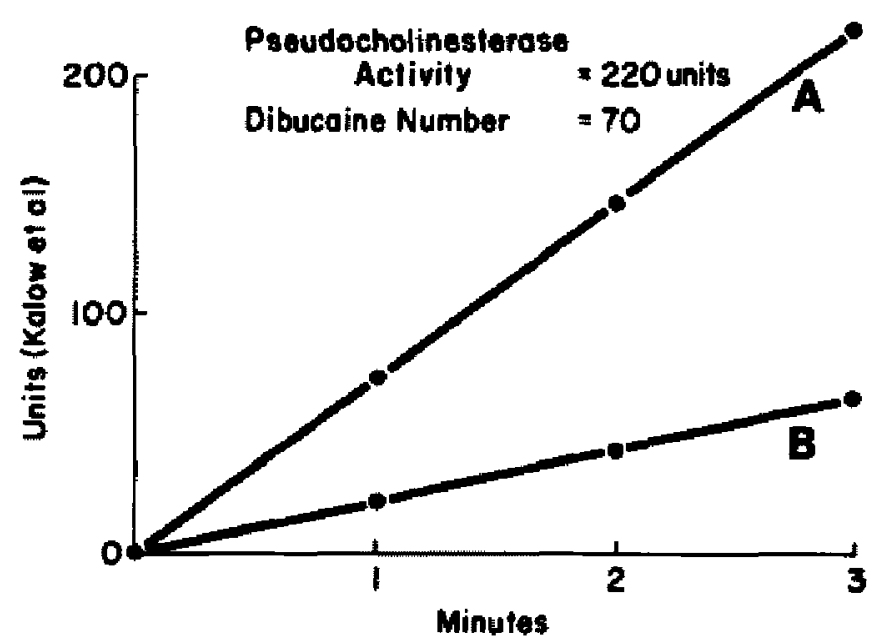

Figune 2. This shows the pseudocholinesterase activity of the patient as measured by hydrolysis of Benzoylcholine alone in A and with Dibucaine and Benzoylcholine in B.

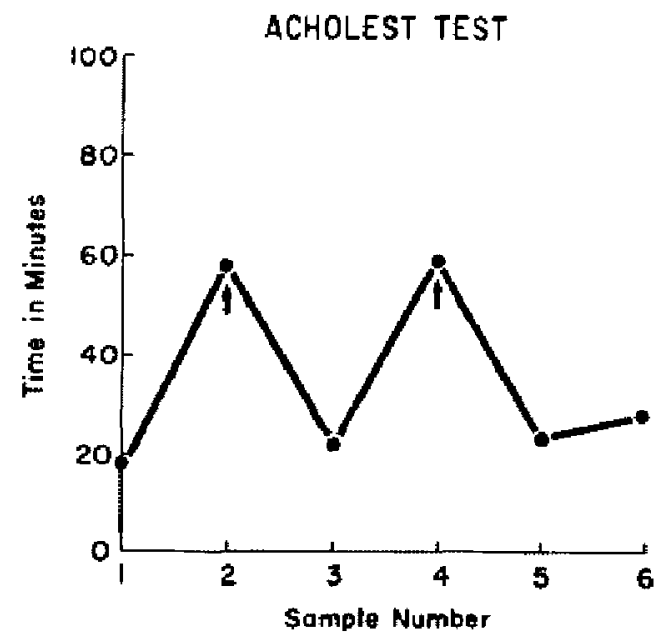

Ficure 3. The plasmacholinesterase activity in this patient as measured by Acholest Test is shown in this figure. Samples are taken at different periods during anesthesia, before and after Pancuronium.

\section{Discussion}

The myotonic syndrome is classified into three clinical entities. ${ }^{3}$

1. Dystrophia myotonica (Steinert's disease) is the severest of the three and characterized by myotonia, muscular dystrophy, frontal baldness, cataract, testicular atrophy, cardiac abnormalities, skeletal changes, endocrine dysfunction, and mental deterioration. The onset of the disease is between $30-50$ years of age.

2. Myotonia congenita (Thomsen's disease), as the name indicates, manifests 


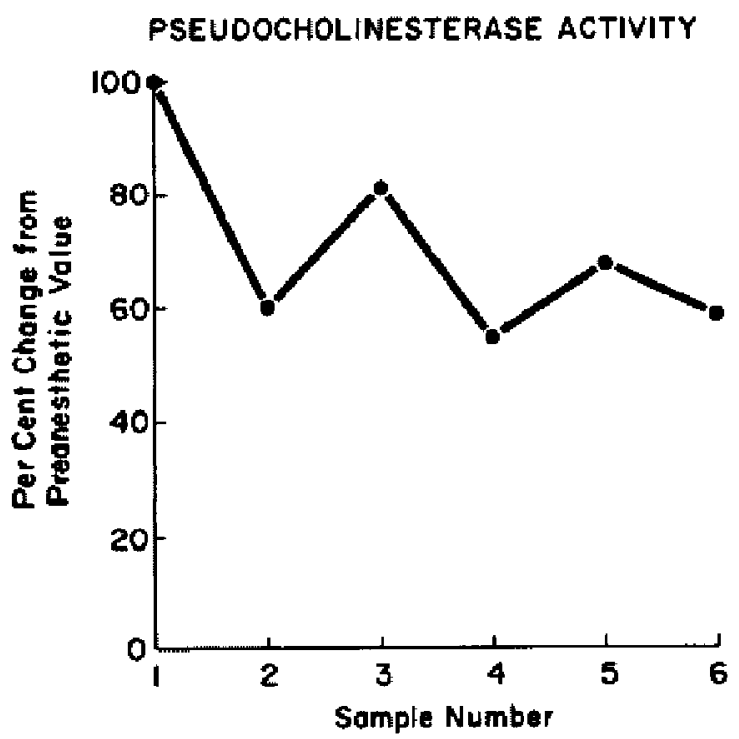

Frcure 4. Plasmacholinesterase activity obtained in this patient as measured by Benzoylcholine hydrolysis is shown in this fgure. Samples are taken at different periods during anesthesia, before and after Pancuronium (see text).

itself at birth or early in childhood. The muscle involvement is fairly widespread with obvious muscular hypertrophy. There is usually no involvement of other systems.

3. Paramyotonia. It is a rare entity, and the characteristic feature is the development of myotonia on exposure to cold and its relief by heat.

Basically, in dystrophia myotonica, the muscle fibers are affected with no involvement of the myoneural junction or the intramuscular nerve fibers. The histobiochemical evidence in the fragmented sarcoplasmic reticulum indicates the primary involvement to be in the red muscle fibers with sparing of the white fibers. ${ }^{\theta}$

The EMG in dystrophia myotonica shows continuous low voltage activity interspaced with a fibrillation-like potential at a higher voltage. A mechanical stimulus, e.g. thenar tap, evokes a burst of rhythmical interference activity of $90-100$ beats/sec, which eventually slows down to low voltage activity.

There is evidence that not only does dystrophia myotonica affect the cardiac and skeletal muscle fibers, but it also affects the endocrine and central nervous systems. Hence, it is a multisystem disease. This should be taken into consideration in the preoperative evaluation of the patient and the selection of the anaesthetic technique.

Clinically, cardiac abnormalities may be present as a cardiomyopathy ${ }^{7.8}$ or as conduction defects. ${ }^{0-11}$ Cardiomyopathy may be primary or secondary to myxoedema or diabetes mellitus.

Gonadal atrophy may cause secondary hyperpituitarism and acromegaly. Sometimes a moderate degree of prognathism may be present. ${ }^{\mathrm{a}}$ The oestrogenic 
effect may cause gynaecomastia and an increase in the total body water and extracellular fluid volumes. ${ }^{\mathrm{z}}$

Glucose metabolism may be deranged and diabetes mellitus is frequent. However, in this case report, the blood sugar was only $55 \mathrm{mg} \%$. This could have been due to hypothyroidism. The basal metabolic rate is also reduced, and the significance of this in the metabolism of drugs is obvious.

Respiratory function is compromised due to the involvement of intercostal and accessory muscles, diaphragm, and laryngeal muscles in the terminal stages. Initially, there is a restrictive element in the reduction of pulmonary function, followed by an obstructive component.

Effect of Temperature. Although the development of myotonia due to cold is the cardinal feature of paramyotonia, it may also occur in dystrophia myotonica. The implication of this factor under anaesthesia is clear as there is a tendency for any patient to become hypothermic. It has been suggested that malignant hyperthermia is associated with intracellular enzymatic disturbances. ${ }^{12-14}$ These are concerned with an inability or actual inhibition of the relaxation phase of muscular contraction. Hoech and Jones"s suggest that "metabolic disorders involving muscle may be a reasonable prototype defining some of the patients susceptible to malignant hyperthermia". Issacs and Barlow ${ }^{10}$ have postulated that there may be an underlying muscular dystrophy in patients who are susceptible to malignant hyperthermia. Further evidence is provided by the fact that procaine amide has a beneficial effect in both syndromes, ${ }^{17}$ although it is not a reliable method of therapy in either one.

Effect of Drugs. As most of the stress has been placed on the development of contracture following succinyldicholine and caution in the use of respiratory depressant drugs, these merit a detailed discussion. Orndahl and Stenberg, ${ }^{18}$ studying the effects of succinyldicholine and decamethonium in these patients, showed that intravenous injections of succinyldicholine (in one case $250 \mathrm{mg}$ ) caused a relatively slow contraction of the muscles followed by a protracted return to the initial position (mechanical response) similar to that which occurs in reptiles and birds. The response was not dose related and a thenar tap could still be elicited after full blockade. Tachyphylaxis was present as in the normal patient. The mechanical response caused by succinyldicholine was enhanced by the prior use of anticholinesterase agents, e.g. neostigmine, probably due to the decreased metabolism of succinyldicholine.

By eltectromyographic studies, Petersen et al. ${ }^{19}$ demonstrated spontaneous electrical activity and mechanical irritability. After succinyldicholine blockade, electrical activity disappeared but the mechanical response persisted, indicating a state of contracture. Paterson, ${ }^{20}$ reporting a case of generalized myotonia after succinyldicholine in a patient with myotonia congenita, mentioned that relaxation occurred 3 to $3 \%$ minutes after a dose of 50 to $75 \mathrm{mg}$.

The patient had twice the normal plasma cholinesterase activity, which may be of significance in this disease. This investigation did not determine whether this increased activity was due to presence of a genetic variant, $\mathbf{E}$ cyanthiana, $\mathrm{La} \mathrm{Du},{ }^{21} \mathrm{C} 5$ variant, or due to an increase in the synthesis of the normal Eu type of cholinesterase. It is interesting to speculate, however, that a routine dose of succinyldicholine will hydrolyse twice as fast as normal in this patient. 
Clinically, the rapid hydrolysis of succinyldicholine may be seen as a transient muscular fasciculation, without the accompanying relaxation. The build-up of endogenous acetylcholine during this period may then follow the fasciculation with a myotonic response.

This abnormal enzyme, E cyanthiana, unlike the Eu type, may split succinyldicholine to acetylcholine and thus rapidly build up a large amount of exogenous acetylcholine. ${ }^{22}$ Succinyldicholine activity is lost prior to action at the neuromuscular junction in sufficient concentration to give relaxation. At the same time, the neuromuscular junction becomes sensitive to exogenous acetylcholine and will give a myotonic response. Further investigations of plasma cholinesterase in this condition may be worth while.

Figures 3 and 4 demonstrate the variations of plasma cholinesterase activity during anaesthesia in this patient. This appears to be due to the drug interaction between plasma cholinesterase and pancuronium. The anticholinesterase activity of pancuronium has been tested and reported both in vivo and in vitro. ${ }^{28}$

The administration of succinyldicholine to patients with dystrophia myotonica is regarded as contraindicated by some authorities. But the inadvertant administration of this drug may still occur. Non-depolarising Relaxants have no effect on the myofibrils and will have no effect on muscle that is in contracture. ${ }^{24}$ However, the prior use of these non-depolarisers may reduce the intensity of the response to succinyldicholine. The usual response to the non-depolarisers on nerve stimulation is present unless the muscle is directly stimulated. In this latter case, e.g. thenar tap, myotonia results.

The use of thiopentone has been regarded as contraindicated in dystrophia myotonica patients because of profound respiratory depression. However, in the study of Orndahl mentioned above, up to $600 \mathrm{mg}$ of hexobarbital were given, and no untoward respiratory depression was mentioned. Dundee ${ }^{25}$ postulated that thiopentone may have a peripheral action on the muscle itself. Perhaps the excessive depression reported was due to unrecognized hypothyroidism or to alterations in serum proteins from endocrine disturbances. It is a relative contraindication and depends on the respiratory or cardiac reserve.

Narcotics. Morphine may be preferable to fentanyl, as the latter is known to cause muscle rigidity.

Halothane. Thiel ${ }^{28}$ has suggested that halothane may not be the anaesthetic of choice because of its tendency to cause postoperative shivering. This shivering may precipitate or make the myotonia worse.

Neostigmine. The $\mathrm{pID}_{50}$ for neostigmine with plasma cholinesterase under normal circumstances is 6.6 (or $2.5 \times 10^{-7} \mathrm{M}$ ). ${ }^{27}$ Neostigmine is bound mainly to the albumin fraction and in theory, then, the dose should be increased. Pinelliz4 reported that moderate clinical improvement was observed with neostigmine in a dystrophia myotonica patient. However, the same speculation that we have made concerning pancuronium, would apply to neostigmine. Persistence of narcotic actions (especially respiratory depression) and the potentiation of the effects of narcotics by anticholinesterases need consideration. ${ }^{28}$

Quinine, procaine amide, cortisone, glucose and insulin, and, lastly, 1/6 molar sodium lactate have been reported to reduce myotonia."

In brief, a dystrophia myotonica patient is likely to present life threatening com- 
plications arising from: (1) cardiomyopathy and conduction defects which may even precipitate Stokes-Adams attacks; (2) hypoxia due either to poor pulmonary function because of the involvement of respiratory muscles by the disease, or due to sustained muscle contracture by the inadvertent use of provocative agents or, (3) endocrine dysfunction, e.g. diabetic acidosis or hypothyroidism.

Taking these points into consideration, this patient was premedicated with atropine alone. As the pulmonary function tests were not grossly abnormal, thiopentone was chosen for induction of anaesthesia. The albumin fraction was elevated in this patient, and as thiopentone is bound to albumin, it was expected that he would require a larger dose than usual. Pancuronium was used for intubation. There was a possibility that because of its anticholinesterase activity it could evoke a myotonic response. However, being a non-depolariser, and at the dosage chosen, it was felt that ideal conditions for intubation would be obtained without necessitating the use of succinyldicholine or deep anaesthesia. (This patient had retrognathia.) The anticipated operative time and the known duration of action of pancuronium were complementary. This relaxant was chosen also for the ease of reversibility and the cardiovascular stability associated with its use.20,80,31 No problems arose from the choice of this relaxant.

Even though, as mentioned above, morphine may be preferable to fentanyl, the latter drug was used because the anaesthetic technique included a relaxant. The half life of fentanyl being relatively short, postoperative narcotic depression would not be anticipated, whether with or without the potentiating effects of neostigmine.

\section{SUMMARY}

In the anaesthetic management of dystrophia myotonica, emphasis should be placed on the fact that it is a multisystem disease. Cardiac, respiratory, and endocrine functions should be considered of greater importance than the myotonic aspects of the disease. The management of a case is described, using pancuronium as the muscle relaxant. Plasma cholinesterase activity was measured and the need for further investigation is suggested.

\section{RÉsumé}

Au cours de l'évaluation préopératoire des porteurs de dystrophie myotonique, il faut insister surtout sur le système cardiovasculaire, le système respiratoire et le système endocrinien car la morbidité et la mortalité sont reliées à ces aspects de la maladie plutôt qu'à la réponse myotonique.

Nous rappelons les effets des agents anesthésiques et des médicaments adjuvants sur l'évolution de cette maladie.

L'activité de la pseudocholinestérase et son inhibition par le pancuronium (Pavulon $^{\mathrm{R}}$ ) ont été étudiées chez ce malade. Nous expliquons nos raisons du choix de la technique anesthésique. 


\section{GENERIC NAME}

Thiopentone

Fentanyl

Pancuronium

Dibucaine

Halothane

Hexobarbital

Decamethonium

Prociaine amide

Neostigmine

Succinyldicholine

\section{TRADE NAME}

Pentothal

Sublimaze

Pavulon

Nupercaine

Fluothane

Evipal

Syncurine

Pronestyl

Prostigmin

Anectine

\section{REFERENCES}

1. McClelland, R.M.A. The myaesthenic state and myotonic syndrome. Brit. I. Anzesth. 32: $81-88(1960)$.

2. Kaufacan, L. Anaesthesia in dystrophia myotonica. Proc. Roy. Soc. Med. 53: 183-188 (1960).

3. CaugheY, J.E. MYrunthopoulos, N.C. Dystrophia myotonica and related disonders. Ed. 1963. Ch. Thomas, Springfield, Ill.

4. Kalow, W. \& LndSAY, H.A. A compromise of optical \& manometric methods for the assay of human cholinesterase. Can. J. Biochem. Physiol. 35: 1305-1307 (1955).

5. KaLow, W. \& GENEST, K. A method for the detection of atypical forms of human serum cholinesterase. Determination of dibucaine numbers. Can. J. Biochem. Physiol. 35: 339-346 (1957).

6. SAMAFA, F.J. \& GERger, J. Biochemical abnormalities of the sarcoplasmic reticulum in muscular dystrophy. New Eng. J. Med. 280: 184-188 (1969).

7. LrTchriend, J.A. A-V dissociation in dystrophia myotonica. Brit. Heart J. 15; 357-359 (1953).

8. Pemrovich, N.J., DunN, M. \& Rekd, W. Mytonica dystrophica with A-V dissociation and Stokes-Adarns attacks. Amer. Heart J. 68: 391-390 (1964).

9. CHuFte, S.C. The heart in myotonia atrophica. Arch. Int. Med. 119: 176-181 (1907).

10. MnIER, P.B. Myotonic dystrophy with eleetrocardiographic abnomalities. Report of a case. Amer. Heart J. 63: 704-707 (1962).

11. Hox, J.M. \& Lambent, E.H.N. Heart disease as the presenting feature of myotonica atrophica, Brit. Heart J. 26: 433-436 (1964).

12. Britr, B.A. KALOw, W. Malignant hyperthermia. Aetiology unknown! Canad. Anaesth. Soc. J. $17: 316(1970)$.

13. Poulocir, R.A. State of contracture in malignant hyperthermia. Correspondence Anesth. 35: 232-233 (1971).

14. Stnozer, G.E. \& BinNCH, C.P. An tn-vitro model of anesthetic hypertonic, hyperpyrexia, halothane-caffine induced muscle contractures. Anesthesiology 35: 465-473 (1971).

15. HoECH, G.P. \& JonEs, G.O. State of contracture in malignant hyperthermia. Correspondence Anesth. 35: 231-232 (1971).

16. Issacs, H. \& BAfLow, M.B. The genetic background to malignant hyperpyrexta revealed by serum creatinine phosphokcinase estimation in asymptomatic relatives. Brit. I. Anaesth. 42: 1077 ( 1970$)$.

17. Bnirt, B.A. Symposium on metabolic effects of anaesthesia. Procaineamide. Royal College of Surgeons. London (1970).

18. ÖRNDARL, $G$. \& STENBERG, $K$. Myotonic human musculature: stimulation with depolatising agents. Acta Medica. Scand. Suppl. 389 to Vol, 172 (1968).

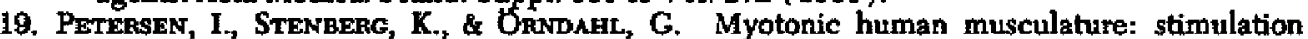
with depolarising agents. Acta Medica. Scand. Suppl. 389 to Vol. 172 (1962).

20. Pategison, I.S. Generalized myotonia following suxamethonium. Brit. J. Anaesth. 34: $340-342$ (1962).

21. Bert, EA Du. Plasma esterase activity and the metabolism of drugs with ester groups. Annals New York Academy Sciences, Vol. 179 ( 1971 ).

22. Brucke, F. Dicholinesters of $\alpha, \omega$-Dicarboxylic acids and related substances. Pharmacological Reviews, Vol. 8, No. 2, pp. 265-335 (1956). 
23. Bennetr, E.J., Ray, Prithy, P., \& Dalal, F.Y. Pancuronitum bromide: anticholinesterase effect. Unpublished data.

24. Muscle Diseases. Proceedings of an International Congress Milan 19-21 May 1969. Editors J.N. Walton, N. Canal, G. Scarlato. Excerpta Medica Amsterdam (1970).

25. Dennex, J,W, Thiopentone in dystrophia myotonia. Anesth. Analg. 31: 257 (1952).

26. Threx, R.E. The myotonic response to suxpmethonium. Brit. J. Anaesth. 39: 815-821 (1967).

27. Barrow, M.E.H. \& Jonnson, J.K. A study of the anticholinesterase and anticurare effects of some cholinesterase inhibitors. Brit. J. Anaesth. 38; 420-431 (1966).

28. Staughter, D., Pansons, J.C., \& Munal, H.D. New Clinical Aspects of the analgesic action of morphine. J.A.M.A. 115; 2058 (1940).

29. SMrTh, G., Procron, D.W., \& SPEnce, A A comparison of some cardiovascular effects of tubocurine and pancuronium in dogs. Brit. J. Anaesth. 42: 923-927 (1970).

30. Kez.mav, G.R. \& Kennedy, B.R. Cardiovascular effects of pancuronium in man. Brit. J. Anaesth. 43: 335-338 (1971).

31. Dobra, A.B., Wiltelam, E., Ghanooni, S., Levy, A.A., \& Thomeas, I.T. Pancuronium bromide (Pavilon ${ }^{\mathrm{E}}$ ) evaluation of its clinical pharmacology. Canad. Anaesth. Soc. J. Vol. 18, No. 5 (1971). 